\title{
Effect of transient ulnar artery compression on radial artery diameter
}

\author{
MUSTAFA ADEM YILMAZTEPE ${ }^{1}$ and ERDEM YILMAZ ${ }^{2}$ \\ Departments of ${ }^{1}$ Cardiology and ${ }^{2}$ Radiology, School of Medicine, Trakya University, Edirne 22030, Turkey
}

Received January 23, 2018; Accepted July 26, 2018

DOI: $10.3892 /$ etm.2018.6632

\begin{abstract}
The transradial approach is widely preferred in coronary procedures. A small radial artery diameter (RAD) is the most important factor affecting successful access. Various maneuvers and medications have been used to increase the RAD and thereby facilitate RA cannulation. Ulnar artery compression (UAC) for $30 \mathrm{~min}$ has been indicated to be effective in increasing the RAD and facilitating RA access. The aim of the present preliminary study was to assess the effect of transient UAC for 1 min on the RAD. A total of 151 patients were included in the present study. RA ultrasonography was performed at the level of the wrist. The UA was compressed for $1 \mathrm{~min}$. The RAD was measured at baseline, at the end of UAC and at 1 min thereafter. The results indicated that the RAD was significantly smaller in diabetic vs. non-diabetic patients $(2.35 \pm 0.43$ vs. $2.50 \pm 0.39 \mathrm{~mm}$, $\mathrm{P}=0.024)$ and in women vs. men $(2.25 \pm 0.38$ vs. $2.56 \pm 0.38 \mathrm{~mm}$, $\mathrm{P}<0.001)$. At the end of UAC, the RAD was increased compared with that at baseline $(2.45 \pm 0.41$ vs. $2.62 \pm 0.41 \mathrm{~mm}, \mathrm{P}<0.001)$, but it started to decrease thereafter, and the RAD measured at $1 \mathrm{~min}$ after stopping UAC was significantly smaller (2.62 \pm 0.41 vs. $2.55 \pm 0.40 \mathrm{~mm}, \mathrm{P}<0.001)$, while remaining significantly larger than that at baseline $(\mathrm{P}<0.001)$. The RA peak systolic flow velocity also increased significantly during UAC ( $35.3 \pm 8.9$ vs. $60.3 \pm 19.2 \mathrm{~cm} / \mathrm{sec}$; $\mathrm{P}<0.001)$. In conclusion, Transient UAC for 1 min significantly increased the RAD and the peak systolic flow velocity. Further studies with clinical endpoints are required for further exploration of the feasibility of this approach.
\end{abstract}

\section{Introduction}

The transradial approach (TRA) is widely preferred in coronary procedures and is the recommended choice of access particularly in the invasive treatment of acute coronary syndromes (1).

Correspondence to: Dr Mustafa Adem Yilmaztepe, Department of Cardiology, School of Medicine, Trakya University, Balkan Campus, Edirne 22030, Turkey

E-mail: mayilmaztepe@yahoo.com

Key words: transradial access, ultrasonography, ulnar artery, radial artery
Lower rates of major vascular complications, improved patient comfort and shorter hospital stay are the major advantages of TRA compared to transfemoral access (2); vascular complications, including hemorrhage or pseudoaneurysm are rarely encountered (3). The most important disadvantages are radial artery spasm (RAS) (4) and RA occlusion (RAO) (5).

A small RA diameter (RAD), difficult access, inexperienced operators and the presence of peripheral arterial disease have been identified as predictors of RA access failure (6). In a recently published study, female sex, older age and short stature were reported as enhancing factors of technical failure risk in TR angiography (7). The RA is a small-sized artery whose diameter ranges from 1.15 to $3.95 \mathrm{~mm}$ (8). Smaller RADs have been associated with vascular complications $(9,10)$. Multiple puncture attempts increase the risk of vasospasm and may result in hemorrhage, dissection, pseudoaneurysm, thrombosis and pain. Radial sheath insertion may lead to endothelial damage and multiple puncture attempts, and increase the risk of endothelial dysfunction (11). A RAD/sheath diameter $(<1 \mathrm{~mm})$ indicated to be a risk factor for RAS (12) and RAO (13). To prevent this damage and safely complete the procedure, vasodilator medications are mainly used. Various maneuvers and medications have been used to increase RAD and enhance RA cannulation (14-16). The strategy of increasing radial artery flow by ulnar artery compression (UAC) has been previously reported (17). In a recently published study, ulnar occlusion for $30 \mathrm{~min}$ increased the RAD and facilitated access (18). However, application of UAC for $30 \mathrm{~min}$ is not feasible in each patient. The aim of the preliminary study was to assess the effect of 1 min of ipsilateral transient UAC on RAD.

\section{Patients and methods}

Patients. A total of 151 consecutive patients who were referred to the Department of Cardiology (Trakya University Hospital, Edirne, Turkey) for coronary angiography between December 2016 and July 2017 were included in the present study. The procedures of the current study were not a part of the routine coronary angiography and USG was performed the day before the coronary angiography procedure. Patients with hemodynamic instability, non-palpable UAs or RAs, those who were on hemodialysis or with a history of RA access were excluded. The present study was approved by the Scientific Research Ethics Committee of Trakya University 
(approval no. 2016/286). All patients provided written informed consent. The study was performed in accordance with the Declaration of Helsinki.

The patients' demographic data and the presence of coronary artery disease risk factors were all recorded.

Evaluation of the effect of UAC on RAD. RA ultrasonography was performed on the day before the coronary angiography procedure, by an experienced radiologist after $10 \mathrm{~min}$ of supine rest (baseline) using a 6-18 $\mathrm{MHz}$ linear array transducer(Mylab 70 XVG; Esaote Medical Systems SpA, Genova, Italy). RAD was measured from two-dimensional gray scale transverse images at the wrist level, $2 \mathrm{~cm}$ proximal to the styloid process. Following the resting measurements, UAC was applied by manual compression for $1 \mathrm{~min}$ at the level of the wrist joint, at Guyon's canal, with complete obliteration of the UA as confirmed through ultrasonographic assessment. During UAC, the RA was continuously observed. The RA peak systolic flow velocity was also measured at baseline and during UAC. The RAD was measured at the end of the UAC (1st minute) and at 1 min after stopping UAC (2nd minute). All images and patient numbers were digitally recorded and the measurements were performed offline. An experienced sonographer, who was blinded to the study design, measured the diameters and blood flow. The average of two values was accepted as the RAD. To evaluate inter-observer variability, the recorded images of 30 randomly selected patients were analyzed by another sonographer. Intra-observer variability was also evaluated by having 10 randomly selected patients re-measured by the same operator.

The sample size was determined according to the estimated increase in the RAD. In a recently published study by Zhou et al (18), $30 \mathrm{~min}$ of UAC caused a 0.11-mm increase in the RAD. A $0.15-\mathrm{mm}$ increase in the RAD was assumed in the present study. For an estimated statistical power of $80 \%$, 114 patients were sufficient for a $0.15-\mathrm{mm}$ increase to reach statistical significance.

Statistical analysis. Statistical analysis was performed using SPSS version 20 for Windows (IBM Corp., Armonk, NY, USA). Categorical variables are expressed as numbers and percentages. A Kolmogor-Smirnov test was used to assess the distribution of variables. Normally distributed continuous variables are expressed as the mean \pm standard deviation and were compared using the independent-samples t-test. Non-normally distributed continuous variables were compared using the Mann-Whitney U test. Categorical values were compared with $\chi^{2}$ test. The change in the RAD and the peak systolic velocity at baseline, during and after UAC were calculated using one-way repeated-measures analysis of variance followed by Bonferroni's post-hoc test for multiple comparisons. Wilcoxon's signed rank test was used for comparison of the peak RA velocity at baseline with that during UAC. For assessing the correlation of non-normally distributed variables, Spearman's rank test was used to calculate the correlation coefficient (r) and its significance. Inter- and intra-observer reliability were evaluated using Kappa (к) statistics. $\mathrm{P}<0.05$ was considered to indicate a statistically significant difference.
Table I. Demographic and clinical data of the patients $(n=151)$.

\begin{tabular}{lc}
\hline Characteristic & Value \\
\hline Age (years) & $63(33-84)$ \\
Male/female & $97 / 54$ \\
BMI $\left(\mathrm{kg} / \mathrm{m}^{2}\right)$ & $28.5 \pm 5.2$ \\
Height $(\mathrm{cm})$ & $165.2 \pm 8.9$ \\
Weight $(\mathrm{kg})$ & $77.6 \pm 14.6$ \\
Diabetes mellitus & $55(36.4)$ \\
Hypertension & $128(84.8)$ \\
Hyperlipidemia & $113(74.8)$ \\
Smoker & $55(36.4)$ \\
CAD & $137(90.7)$ \\
$\beta$-blockers & $104(68.9)$ \\
Ca-channel blockers & $74(49)$ \\
ACE-I/ARB & $99(65.6)$ \\
Long-acting nitrates & $41(27.2)$
\end{tabular}

Values are expressed as the mean \pm standard deviation, median (range) or n (\%). ACE-I, angiotensin-converting enzyme inhibitor; $\mathrm{ARB}$, angiotensin II receptor blocker; BMI, body mass index; CAD, coronary artery disease.

Table II. Demographic, clinical data and radial artery diameter by sex.

\begin{tabular}{lccr}
\hline Characteristic & Male & Female & P-value \\
\hline $\mathrm{N}(\%)$ & $97(36.4)$ & $54(63.6)$ & \\
Age $($ years $)$ & $63(33-81)$ & $62(36-84)$ & 0.910 \\
Height $(\mathrm{cm})$ & $169.2 \pm 7.4$ & $158.1 \pm 7.1$ & $<0.001$ \\
Weight $(\mathrm{kg})$ & $80.1 \pm 14.1$ & $72.9 \pm 14.9$ & 0.006 \\
BMI $\left(\mathrm{kg} / \mathrm{m}^{2}\right)$ & $28.0 \pm 4.6$ & $29.3 \pm 6.1$ & 0.159 \\
Diabetes mellitus & $30(30.9)$ & $25(46.3)$ & 0.060 \\
Hypertension & $82(84.5)$ & $46(85.2)$ & 0.915 \\
Hyperlipidemia & $76(78.4)$ & $37(68.5)$ & 0.182 \\
Smoker & $43(44.3)$ & $12(22.2)$ & 0.007 \\
CAD & $94(96.9)$ & $43(79.6)$ & $<0.001$ \\
$\beta$-blockers & $69(71.1)$ & $35(64.8)$ & 0.421 \\
Ca-channel blockers & $46(47.4)$ & $28(51.9)$ & 0.602 \\
ACE-I/ARB & $64(66.0)$ & $35(64.8)$ & 0.885 \\
Long-acting nitrates & $23(23.7)$ & $18(33.3)$ & 0.203 \\
RAD (mm) & $2.56 \pm 0.38$ & $2.25 \pm 0.38$ & $<0.001$ \\
\hline
\end{tabular}

Values are expressed as mean \pm standard deviation, median (range) or n (\%). ACE-I, angiotensin-converting enzyme inhibitor; ARB, angiotensin II receptor blocker; BMI, body mass index; CAD, coronary artery disease; RAD, radial artery diameter.

\section{Results}

Baseline characteristics. A total of 151 patients were enrolled in the present study. The characteristics of the patients at baseline are presented in Table I. The mean resting RAD 
Table III. Demographic, clinical data and radial artery diameter based on diabetes diagnosis.

\begin{tabular}{lccr}
\hline Characteristic & Diabetic & Not diabetic & P-value \\
\hline $\mathrm{N}(\%)$ & $55(36.4)$ & $96(63.6)$ & $62(38-84)$ \\
Age (years) & $63(33-81)$ & $67 / 29$ & 0.227 \\
Male/Female & $30 / 25$ & $166.4 \pm 8.8$ & 0.060 \\
Height $(\mathrm{cm})$ & $163.2 \pm 8.9$ & $75.4 \pm 14.6$ & 0.035 \\
Weight $(\mathrm{kg})$ & $81.5 \pm 13.9$ & $27.2 \pm 4.5$ & 0.011 \\
BMI $\left(\mathrm{kg} / \mathrm{m}^{2}\right)$ & $30.7 \pm 5.6$ & $75(78.1)$ & $<0.001$ \\
Hypertension & $53(96.4)$ & $67(69.8)$ & 0.001 \\
Hyperlipidemia & $46(83.6)$ & $40(41.7)$ & 0.059 \\
Smoker & $15(21.3)$ & $82(85.4)$ & 0.077 \\
CAD & $55(100)$ & $61(63.5)$ & 0.003 \\
$\beta$-blockers & $43(78.2)$ & $48(50)$ & 0.062 \\
Ca-channel blockers & $26(47.3)$ & $56(58.3)$ & 0.747 \\
ACE-I/ARB & $43(78.2)$ & $21(21.9)$ & 0.014 \\
Long-acting nitrates & $20(36.4)$ & $2.50 \pm 0.39$ & 0.054 \\
RAD (mm) & $2.35 \pm 0.43$ & 0.024 \\
\hline
\end{tabular}

Values are expressed as mean \pm standard deviation, median (range) or n (\%). ACE-I, angiotensin-converting enzyme inhibitor; ARB, angiotensin II receptor blocker; BMI, body mass index; CAD, Coronary artery disease; RAD, radial artery diameter.

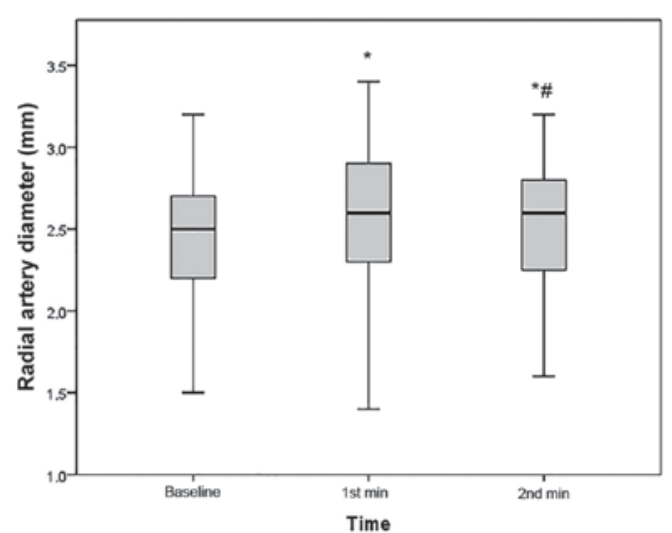

Figure 1. Change in RAD with UAC. Horizontal lines indicate the median 25 th and 75 th percentiles. Baseline, resting RAD; 1st minute, RAD measured at the end of UAC performed for $1 \mathrm{~min}$; 2nd minute, RAD measured $1 \mathrm{~min}$ after stopping UAC. ${ }^{*} \mathrm{P}<0.001$ vs. Baseline; ${ }^{\#} \mathrm{P}<0.001$ vs. 1 st minute. RAD, radial artery diameter; UAC, ulnar artery compression.

was $2.45 \pm 0.41 \mathrm{~mm}$. The baseline characteristics of female and male, and diabetic and non-diabetic patients were also compared and are presented in Tables II and III. The RAD was significantly smaller in diabetic vs. non-diabetic patients ( $2.35 \pm 0.43$ vs. $2.50 \pm 0.39 \mathrm{~mm}, \mathrm{P}=0.024)$ and in women vs. men (2.25 \pm 0.38 vs. $2.56 \pm 0.38 \mathrm{~mm}, \mathrm{P}<0.001)$. A weak but significant correlation of baseline RAD with the body height and weight was identified $(\mathrm{r}=0.313, \mathrm{P}<0.001$; and $\mathrm{r}=0.328$, $\mathrm{P}<0.001$, respectively; data not shown). However, the correlation between the body mass index and the baseline RAD was not significant ( $\mathrm{r}=0.137, \mathrm{P}=0.093$; data not shown).

Efficacy of 1 min of UAC to increase the RAD. Compared with the baseline, the RAD significantly increased after UAC $(2.45 \pm 0.41$ vs. $2.62 \pm 0.41 \mathrm{~mm}, \mathrm{P}<0.001$; Fig. 1$)$. The increase in RAD was $0.17 \pm 0.09 \mathrm{~mm}$. In comparison with that immediately after $1 \mathrm{~min}$ of UAC, the mean RAD at 1 min after stopping UAC was significantly decreased ( $2.62 \pm 0.41$ vs. $2.55 \pm 0.40 \mathrm{~mm}, \mathrm{P}<0.001)$; however, it was still larger than the baseline RAD $(\mathrm{P}<0.001$; Fig. 1$)$. The RA peak systolic flow velocity also significantly increased during UAC ( $35.3 \pm 8.9$ vs. $60.3 \pm 19.2 \mathrm{~cm} / \mathrm{sec}, \mathrm{P}<0.001)$.

Regarding intra-observer reliability, as assessed using $\kappa$ statistics, an almost perfect agreement was determined $(\kappa=0.819)$, while assessment of inter-observer reliability indicated a substantial agreement $(\kappa=0.710)$.

\section{Discussion}

The present study demonstrated that transient ipsilateral UAC for 1 min increases the RAD and the RA peak systolic flow velocity. TR access is the recommended choice for coronary procedures, but there are certain limitations, e.g., RAS and RAO. The thicker muscular layer and the predominance of $\alpha$ receptors make the RA naturally prone to spasm. To overcome vasospasm, several techniques and co-medications have been used $(4,19,20)$. Sedation, smaller-size hydrophilic sheaths and catheters, and vasodilatory cocktails are widely used to prevent spasm.

Hypotension and small-sized, deeply located RAs increase the difficulty of successful puncture, particularly for less experienced operators. Pre-procedural anxiety, pain during local anesthetic injection or puncture attempts may also cause vasospasm. Sedatives given to overcome anxiety may cause hypotension and loss of RA pulse, which complicates successful puncture. As the number of attempts increases, the RA also becomes more susceptible to spasm (21).

A small-diameter RA is the most important factor that affects successful access. Similar to the results of previous 
studies, the RAD determined in the present study ranged from 1.3-3.2 $\mathrm{mm}$ (mean value, $2.45 \pm 0.41 \mathrm{~mm}$ ) (8). The RAD is significantly smaller in women and patients with diabetes, and may be as small as $1.3 \mathrm{~mm}$, smaller than $5-\mathrm{F}$ sheaths or catheters that are used in the majority of coronary procedures performed via the radial route. It was indicated that a smaller RAD, particularly an RA internal diameter to sheath outer diameter ratio of $<1$, is a major predictor of RAS (12). Of note, for patients of small stature, diabetics and female patients, RA ultrasonography prior to coronary angiography may be helpful to prevent access site complications.

Various drugs and maneuvers have been used to dilate the RA and facilitate radial RA (14-16). Transient ipsilateral UAC, by directing blood flow to non-UAs, mainly increases radial flow (17). UAC was reported to be effective in reducing RAO after TRA (22-25). In a recent study by Kaplanoglu and Beton (26), the effects of 1 min of UAC on radial artery diameter and consecutive radial artery compression on ulnar artery diameter were assessed. Their results were in line with those of the present study, indicating an increase in the RAD $(2.2+0.4$ vs. $2.4+04 \mathrm{~mm}, \mathrm{P}<0.001)$ and blood flow with UAC. In addition to this previous study, the present study demonstrated that the RAD at 1 min after the end of UAC was still significantly larger than the baseline value. In another recently published study, UAC for 30 min significantly increased the $\operatorname{RAD}(2.28 \pm 0.44$ vs. $2.39 \pm 0.50 \mathrm{~mm}, \mathrm{P}=0.042)$ (18). The authors stated that UAC facilitated radial access with fewer puncture attempts and reduced vascular access time. In contrast to the abovementioned study, UAC was applied in the present study for $1 \mathrm{~min}$ only, and this shorter time was also sufficient to increase the RAD. Based on the study by Zhou et al (18), it may be assumed that the enlargement in the RAD achieved in the present study may also facilitate RA access and decrease RAS; however, this requires further investigation.

Of note, the present study had certain limitations. First, it was a single-center study. It was demonstrated that UAC for 1 min was effective in dilating the RA, but further studies with clinical endpoints are required to assess the real-life consequences of UAC. Finally, although RAD was still larger than the baseline measurement at 1 min after UAC, data regarding the duration of RA enlargement are currently lacking.

In conclusion, the application of UAC for 1 min increases the RAD, which may be performed as a strategy to facilitate the TRA in coronary procedures. Further prospective, randomized studies with clinical endpoints are required to assess the feasibility of this method.

\section{Acknowledgements}

Not applicable.

\section{Funding}

No funding was received.

\section{Availability of data and materials}

The datasets used and/or analyzed during the current study are available from the corresponding author on reasonable request.

\section{Authors' contributions}

MAY and EY performed the enrolment of the patients, data collection and ultrasound imaging. All authors read and approved the final manuscript.

\section{Ethical approval and consent to participate}

The present study was approved by the Scientific Research Ethics Committee of Trakya University. All patients provided written informed consent.

\section{Patient consent for publication}

Not applicable.

\section{Competing interests}

The authors declare that they have no competing interests.

\section{References}

1. Ibanez B, James S, Agewall S, Antunes MJ, Bucciarelli-Ducci C, Bueno H, Caforio ALP, Crea F, Goudevenos JA, Halvorsen S, et al: 2017 ESC Guidelines for the management of acute myocardial infarction in patients presenting with ST-segment elevation: The Task Force for the management of acute myocardial infarction in patients presenting with ST-segment elevation of the European Society of Cardiology (ESC). Eur Heart J 39: 119-177, 2018.

2. Bhat FA, Changal KH, Raina H, Tramboo NA and Rather HA Transradial versus transfemoral approach for coronary angiography and angioplasty-A prospective, randomized comparison. BMC Cardiovasc Disord 17: 23, 2017.

3. Tatli E, Buturak A, Cakar A, Vatan BM, Degirmencioglu A, Agac TM, Kilic H, Gunduz H and Akdemir R: Unusual vascular complications associated with transradial coronary procedures among 10,324 patients: Case based experience and treatment options. J Interv Cardiol 28: 305-312, 2015 ,

4. Kwok CS, Rashid M, Fraser D, Nolan J and Mamas M: Intra-arterial vasodilators to prevent radial artery spasm: A systematic review and pooled analysis of clinical studies. Cardiovasc Revasc Med 16: 484-490, 2015,

5. Dharma S, Kedev S, Patel T, Rao SV, Bertrand OF and Gilchrist IC: Radial artery diameter does not correlate with body mass index: A duplex ultrasound analysis of 1706 patients undergoing trans-radial catheterization at three experienced radial centers. Int J Cardiol 228: 169-172, 2017.

6. Guedes A, Dangoisse V, Gabriel L, Jamart J, Chenu P, Marchandise B and Schroeder E: Low rate of conversion to transfemoral approach when attempting both radial arteries for coronary angiography and percutaneous coronary intervention: A study of 1,826 consecutive procedures. J Invasive Cardiol 22: 391-397, 2010.

7. Trobs M, Achenbach S, Plank PM, Marwan M, Röther J, Klinghammer L, Blachutzik F and Schlundt C: Predictors of technical failure in transradial coronary angiography and intervention. Am J Cardiol 120: 1508-1513, 2017.

8. Yoo BS, Yoon J, Ko JY, Kim JY, Lee SH, Hwang SO and Choe KH: Anatomical consideration of the radial artery for transradial coronary procedures: Arterial diameter, branching anomaly and vessel tortuosity. Int J Cardiol 101: 421-427, 2005.

9. Abazid RM, Smettei OA, Mohamed MZ, Kattea MO, Suresh A, Beshir Y and Sakr H: Radial artery ultrasound predicts the success of transradial coronary angiography. Cardiol J 24: 9-14, 2017.

10. Mattea V, Salomon C, Menck N, Lauten P, Malur FM, Schade A, Steinborn F, Costello-Boerrigter L, Neumeister A and Lapp H: Low rate of access site complications after transradial coronary catheterization: A prospective ultrasound study. Int J Cardiol Heart Vasc 14: 46-52, 2016.

11. Tak BT, Balci KG, Erken H, Gerede DM, Tak S, Göksülük H, Turhan S and Erol C: Evaluation of endothelial dysfunction with flow-mediated dilatation after transradial coronary angiography. Acta Cardiol 72: 305-310, 2017. 
12. van der Heijden D, van Leeuwen MA, Janssens GN, Hermie J, Lenzen MJ, Ritt MJ, van de Ven PM, Kiemeneij F and van Royen N: Endothelial dysfunction and the occurrence of radial artery spasm during transradial coronary procedures: The ACRA-Spasm study. EuroIntervention 12: 1263-1270, 2016.

13. Sinha SK, Jha MJ, Mishra V, Thakur R, Goel A, Kumar A, Singh AK, Sachan M, Varma CM and Krishna V: Radial artery occlusion-incidence, predictors and Long-term outcome after TRAnsradial catheterization: Clinico-Doppler ultrasound-based study (RAIL-TRAC study). Acta Cardiol 72: 318-327, 2017.

14. Beyer AT, Ng R, Singh A, Zimmet J, Shunk K, Yeghiazarians Y, Ports TA and Boyle AJ: Topical nitroglycerin and lidocaine to dilate the radial artery prior to transradial cardiac catheterization: A randomized, placebo-controlled, double-blind clinical trial: The PRE-DILATE study. Int J Cardiol 168: 2575-2578, 2013.

15. Majure DT, Hallaux M, Yeghiazarians Y and Boyle AJ: Topical nitroglycerin and lidocaine locally vasodilate the radial artery without affecting systemic blood pressure: A dose-finding phase I study. J Crit Care 27: 532.e9-e13, 2012.

16. Ünal S, Açar B, Yayla C, Balci MM, Ertem AG, Kara M, Maden O, Temizhan A, Tola M and Balbay Y: Manual heating of the radial artery (Balbay maneuver) to facilitate radial puncture prior to transradial coronary catheterization. Rev Port Cardiol 36: 409-414, 2017 (In English, Portuguese)

17. Pancholy SB, Heck LA and Patel T: Forearm arterial anatomy and flow characteristics: A prospective observational study. J Invasive Cardiol 27: 218-221, 2015.

18. Zhou ZM, Yan ZX, Nie B, Guo YH and Zhou YJ: Transient ulnar artery compression facilitates transradial access. Medicine (Baltimore) 95: e5491, 2016.

19. Koga S, Ikeda S, Futagawa K, Sonoda K, Yoshitake T, Miyahara Y and Kohno S: The use of a hydrophilic-coated catheter during transradial cardiac catheterization is associated with a low incidence of radial artery spasm. Int J Cardiol 96: 255-258, 2004.
20. Tatli E, Yilmaztepe MA, Vural MG, Tokatli A, Aksoy M, Ağaç MT, Çakar MA, Gündüz H and Akdemir R: Cutaneous analgesia before transradial access for coronary intervention to prevent radial artery spasm. Perfusion 33: 110-114, 2018.

21. Jia DA, Zhou YJ, Shi DM, Liu YY, Wang JL, Liu XL, Wang ZJ, Yang SW, Ge HL, Hu B, et al: Incidence and predictors of radial artery spasm during transradial coronary angiography and intervention. Chin Med J (Engl) 123: 843-847, 2010

22. Koutouzis MJ, Maniotis CD, Avdikos G, Tsoumeleas A, Andreou C and Kyriakides ZS: Ulnar artery transient compression facilitating radial artery patent hemostasis (ULTRA): A novel technique to reduce radial artery occlusion after transradial coronary catheterization. J Invasive Cardiol 28: 451-454, 2016.

23. Tian J, Chu YS, Sun J and Jiang TM: Ulnar artery compression: A feasible and effective approach to prevent the radial artery occlusion after coronary intervention. Chin Med J (Engl) 128: 795-798, 2015.

24. Bernat I, Bertrand OF, Rokyta R, Kacer M, Pesek J, Koza J, Smid M, Bruhova H, Sterbakova G, Stepankova L and Costerousse O: Efficacy and safety of transient ulnar artery compression to recanalize acute radial artery occlusion after transradial catheterization. Am J Cardiol 107: 1698-1701, 2011.

25. Pancholy SB, Bernat I, Bertrand OF and Patel TM: Prevention of radial artery occlusion after transradial catheterization: The PROPHET-II randomized trial. JACC Cardiovasc Interv 9: 1992-1999, 2016.

26. Kaplanoglu $\mathrm{H}$ and Beton O: Flow and diameter changes of forearm arteries during temporary unilateral reciprocal occlusion: A prospective observational study. J Clin Ultrasound 45: 197-203, 2017. 